\title{
Simple and Not So Simple Models for Compartment Fires
}

\author{
M. R. CURTAT and X. E. BODART \\ Groupe Recherche Service Feu \\ Centre Scientifique et Technique du Bâtiment \\ 84, Av. Jean Jaurès, Champs s/Marne 77420, France
}

Abstract

Simple predictive models can be very useful for engineering applications or education in fire safety. Two aspects of compartment fires are addressed here : the growing fire (risk of flashover) and the fully developped fire (fire resistance problems). For each aspect, two predictive methods are presented : a simple mode1 needing small calculation equipment and a computer code based on a zone model. Some results are given as examples showing the possibilities and limits of these methods.

Keywords : Compartment fire - Fire modelinng - Fire safety engineering.

\section{INTRODUCTTON}

Different types of models have been written during the last decade, that can be used as prediction tools for compartment fires: stochastic models, deterministic field or zone models or correlation formulas from empirical or computer results. Field models, based on local equations, lead to codes demanding large computer capabilities with the theoretical advantage of a more rigorous physical description. The concept of zone model for compartment fire has been used to predict the evolution of several variables in the fire growth process. The computer codes based on zone models need smaller memory size and CPU time than the codes based on field models, with the theoretical drawback of more approximate physical description. Correlation formulas using dimensionnal analysis and/or simple equations can give approximate predictions with little computation work. Stochastic models are of a different type but could be used with deterministic models (if not too big) in coupled deterministic and stochastic model1ing (10).

For short term applications in Fire Safety, a compromise has to be made between required precision, computation capabilities and cost, and size of a global model and code for Fire Safety evaluation, in which compartment fire is an element among others. The continuous progress in computer performances and the desired evolution of an integration of the different elements of Fire Safety are in favor of an increasing use of tools such as the simple - or not very complex - models presented in this paper. 
combustible linings or walls (8). The simple version of ISBA uses a numerical approach giving a very quick integration of the set of differential equations corresponding to the equations of conservation of mass and energy in upper and lower gaseous zones and the discretized expressions of the equation of heat diffusion (4). The main variables that are calculated in function of time are: rate of heat release, temperatures of upper and lower zones, height of the thermal interface, concentration of oxygen and unburnt fuel in upper layer. The pyrolysis rate evolution has to be given as input data. The typical cPU time is about $1 / 10$ of the duration of the fire on a VAX-VMS 11/780 system.

To illustrate the predictive capabilities of ISBA, a comparison of TISBA (Computed temperature of upper layer) and TEXP (averaged measured temperature of upper layer) is shown in Figure 2 for three tests. The references of the tests are given in Table 1 . A very good agreement is observed for the sofa (1) and the wood crib (D) fires. The agreement is poorer for the foam slab fire ( $\Delta$ ) : the computation was made with a rough (1inearized) description of the equivalent radius of the pyrolyzing surface for this simple version of ISBA though a more complex description is necessary (5).

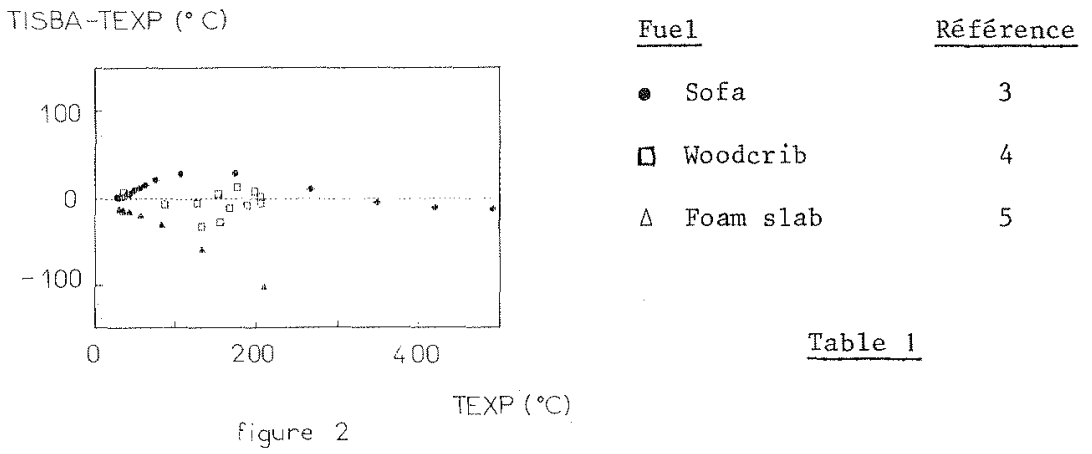

In order to present a certain number of results from (a), prediction (TCoR) were gathered, versus TEMPER several, TEMPER being TEXP tests values (from ref. (2), (3), (4), (6), (7)) or TISBA predictions from some examined fire situations (see Figure 3 giving two evolutions of $\dot{\mathrm{m}}$ and Tables 2 and 3 showing the input data). We chose the interval $400-600{ }^{\circ} \mathrm{C}$ as a definition for a critical temperature range (9) and modified the results from (a) by introducing a factor 0.8 . The results are given in Figure 4: the standard deviation in about $100^{\circ} \mathrm{C}$ in the critical interval, if we except the highest TCOR values corresponding to expanded polystyrene walls. Deriving general conclusions would of course need a much broader set of experimental results and a deeper analysis. Nevertheless the present work gives a new light on the possibilities of the two predictive approaches retained, on giving very quick but approximate results, the other based on more physical basis and needing a numerical solution. 
The prediction of an average upper gas temperature - among several possible variables describing the fire - is not sufficient for a precise description of the growth of a fire but can give precious information about the risk of ignition of items exposed to fire and then the risk of flashover. A model, as simple as possible, for predicting the evolution of this temperature could be used by any person who needs approximate answers one cannot get from conventional tests results. An analytical expression of the evolution of the upper gas temperature during the growth period of a fire was derived by Mc CAFFREY (1) and QUINTIERE (2). The variables $X_{1}$ and $X_{2}$ used in this correlation were obtained by writing the conservation of energy equation under a simple way where, in particular, the heat exchange between gas in upper layer and walls (including ceiling and floor) is linearized in :

where $h_{\text {cond }}$ is a conductance term :

$$
\mathrm{h}_{\text {cond }} \cdot\left(\mathrm{T}_{\mathrm{u}}-\mathrm{T}_{0}\right)
$$

$$
\begin{array}{r}
(\mathrm{K} \rho \mathrm{c} / \mathrm{t})^{1 / 2} \text { for } t<\mathrm{t}_{\mathrm{p}} \\
\mathrm{K} / \mathrm{e} \text { for } t>\mathrm{t}_{\mathrm{p}} \\
\text { with } t_{\mathrm{p}}=(\rho \mathrm{c} / \mathrm{K}) \cdot(\rho / 2)^{2}
\end{array}
$$

An algebra was defined in ref.(2) to take into account the caseof different thermal properties of the walls of a given room.

With $\mathrm{X}_{1}=Q /\left(\mathrm{g}^{1 / 2} \cdot \mathrm{C}_{\mathrm{p}} \cdot \rho_{0} \cdot \mathrm{T}_{0} \cdot \mathrm{A}_{\mathrm{op}} \cdot \mathrm{H}_{\mathrm{op}}^{1 / 2}\right)$
and $\mathrm{X}_{2}=\mathrm{h}_{\text {cond }} \cdot \mathrm{A}\left(\mathrm{g}^{1 / 2} \cdot \mathrm{C}_{\mathrm{p}} \cdot \rho_{\mathrm{O}} \cdot \mathrm{A}_{\mathrm{op}} \cdot \mathrm{H}_{\mathrm{op}}^{1 / 2}\right)$

TEXP-TO $\left({ }^{\circ} \mathrm{C}\right)$

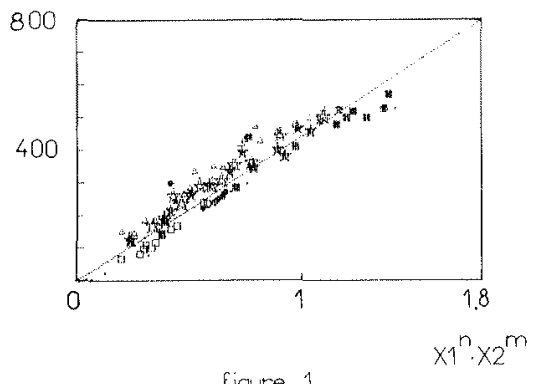

figure 1
$(\mathrm{TEXP}-\mathrm{TO}) / \mathrm{TO}=1.6\left(\mathrm{X}_{1}\right)^{\mathrm{m}}\left(\mathrm{X}_{2}\right)^{\mathrm{n}}$

$\mathrm{n}=2 / 3, \mathrm{~m}=-1 / 3$

The results of a comparison between TEXP - T0 and the predictions from (a) are shown in Figure 1 for 8 data sets (2).

The Fire Research Group of CSTB has been developping since 1979 zone models and computer codes of compartment fires. A recent version of ISBA code (Incendie Simulé dans un BAtiment) was simplified in order to reduce CPU time: the main modifications consisted of a simpler description of the pyrolysis rate and a new writing of the differential equations. The basic physical contents of the model are almost similar to what can be found in the HARVARD mode1.1978 (5). This ISBA version can only address fires caused by burning items located in the lower part of the room. An other version, more complex, can consider the contribution of 


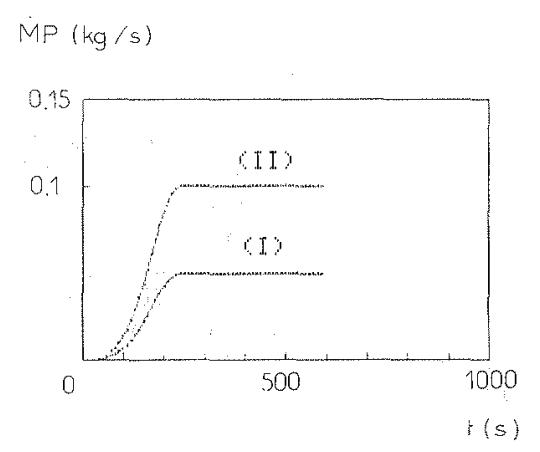

figure 3

$$
\mathrm{H}_{\mathrm{c}}=15 \cdot 10^{6} \mathrm{Jkg}^{-1}
$$

Room size :

(s) $4 \mathrm{~m} \times 3 \mathrm{~m} \times 2.5 \mathrm{~m}$

(1r) $8 \mathrm{mx} 6 \mathrm{~m} \times 2.5 \mathrm{~m}$

Opening :

(d) $: 0.8 \mathrm{~m} \times 2 \mathrm{~m}$

(dd) $: 1.6 \mathrm{~m} \times 2 \mathrm{~m}$

(w) : $1 \mathrm{mx} 1 \mathrm{~m}$, at $1 \mathrm{~m}$ from floor.

\begin{tabular}{l} 
ROOM \\
\hline S \\
S \\
$S$ \\
$S$ \\
$S$ \\
$S$ \\
S \\
S \\
S \\
S \\
LR \\
S \\
S \\
LR
\end{tabular}

\section{OPENING}

$\mathrm{D}$
$\mathrm{D}$
$\mathrm{D}$
$\mathrm{D}$
$\mathrm{D}$
$\mathrm{D}$
$\mathrm{D}$
$\mathrm{D}$
$\mathrm{W}$
$\mathrm{D} D$
$\mathrm{D}$
$\mathrm{W}$
$\mathrm{DD}$
$\mathrm{D}$

Wa11 material: concrete (c), aerated concrete (ac), expanded polystyrene (eps), wood (wo)

\section{TABLE 2}

\begin{tabular}{lccccc}
\multicolumn{1}{l}{ MATERTAL } & $\mathrm{e}$ & $\mathrm{k}$ & $\rho$ & $\mathrm{c}$ & $\varepsilon$ \\
Concrete & 0.1 & 1.6 & 2400 & 750 & 1 \\
Aerated concrete & 0.1 & 0.26 & 500 & 960 & 1 \\
Wood & 0.1 & 0.12 & 540 & 2500 & 1 \\
Expanded polystyrene & 0.1 & 0.034 & 20 & 1500 & 1
\end{tabular}

Thermal propertie of walls (S.I. units)

TABLE 3 


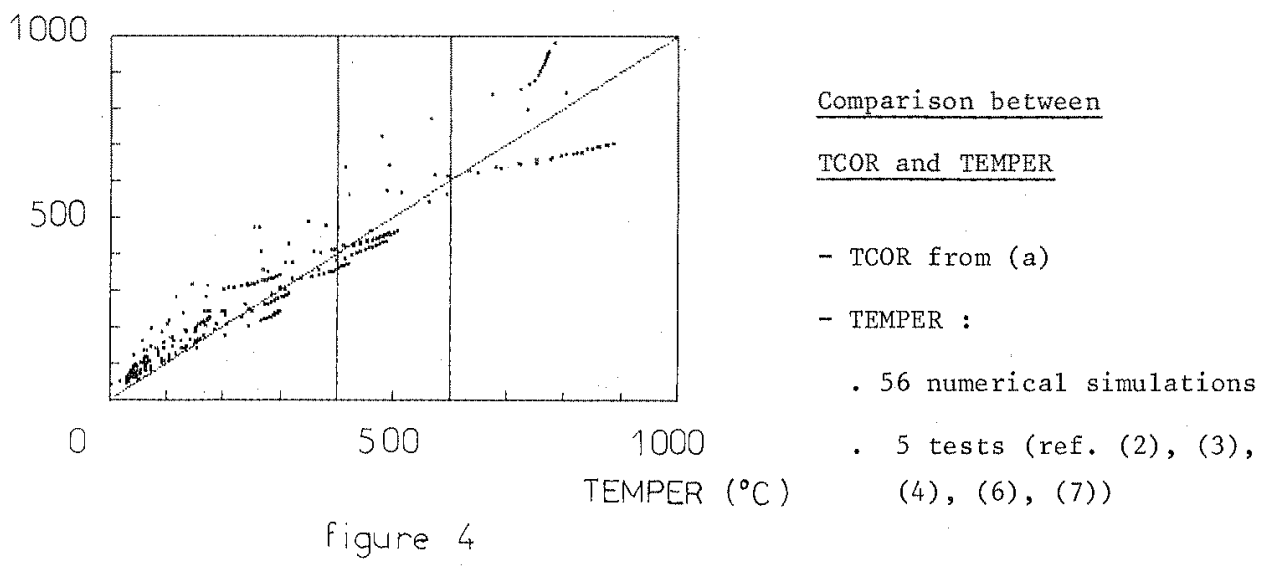

\section{POST - FLASHOVER FIRE}

During the last twenty years, several numerical approaches were developped for the prediction of post-flashover fire temperatures. KANAGOE and SEKINE (11) presented a graphical technique for obtaining approximate solutions in 1963. More recently, computer was used to solve the coupled set of differential (and/ or algebraic) equations derived from heat and mass balances in the gaseous internal zone (assumed to be well-stirred), and the equation of heat diffusion through the walls - References (12) and (13) are examples of more recent works.

Babrauskas proposed in 1981 (14) an approximate calculation method for determining post-flashover fire temperatures in a compartment containing a single ventilation opening. A theoretical model (15) and a computer code (13) were assumed appropriate and adequate : from computed results a closed-form approximation was derived by curve-fitting. The choice was made to write the average gas temperature as :

$$
\mathrm{T}_{\mathrm{g}}=\mathrm{T}_{0}+\left(\mathrm{T}^{*}-\mathrm{T}_{0}\right) \cdot \theta_{1} \cdot \theta_{2} \cdot \theta_{3} \cdot \cdot
$$

where $\mathrm{T}^{*}=1725^{\circ} \mathrm{C}$ is the value of an "adiabatic" temperature giving the best agreement in the range of interest and where the $\theta$ factors represent the influence of burning rate stoichiometry, thermal losses (steady or transient) at the walls, opening height effect, and combustion efficiency (see (14) for expression of $\theta$ factors). The agreement between the results from this closed-form expression and the computer code calculation results was found to be within $+-3 \%$. An approximate fire temperature can be calculated very quickly through expression (b) on a small microcomputer and form an useful input for the prediction of the thermostructural response of fire-exposed elements. 
The evolution of the rate of fuel release has of course to be given in this calculation method (this is a limitation for all the present methods), as the description of the room, wall properties. Then the input data needed are approximately the same as for more complex computerized methods.

We developped recently at CSTB a theoretical model and a computer code of post-flashover fire based on the same basic assumptions as in (13). The main features of CSTB model are described at references ( 16 and 17). The typical CPU time on a VAX-VMS $11 / 780$ is about $10 \mathrm{sec}$. for a simulation of a $30 \mathrm{~min}$ fire.

An example of prediction of gas temperature is shown at Figure 5. The experimental values are obtained by averaging 20 thermocouples outputs. The test is $n^{\circ} 8$ in Ref. (18).

The closed-form expression of Ref. (14), called here CF, and the CSTB model Zl are then two possible tools for an engineering approach of some aspects of Fire Safety. As the CPU times are short for both computer codes, they could be introduced in a coupled deterministic-stochastic approach.

Some comparisons were made between the predictions from $\mathrm{CF}$ and $\mathrm{Z} 1$. The fire situations are described in Table 4. Two mass loss rate evolutions were examined (Figure 6). The results on gas temperature are given on Figure 7 under the form TCF versus TZ1. A very good agreement is observed for concrete and expanded polystyrene walls. The agreement is worse for aerated concrete and wooden walls. The mean value of TCF-TZ1 is $-5^{\circ} \mathrm{C}$ and the standard deviation is about $150{ }^{\circ} \mathrm{C}$. A complete analysis of the observed differences between these two calculated results would necessitate a critical examination of the predictive capability of expression (b) as a deeper evaluation of $Z 1$ model, on the basis of a comparison with a larger number of experimental results.

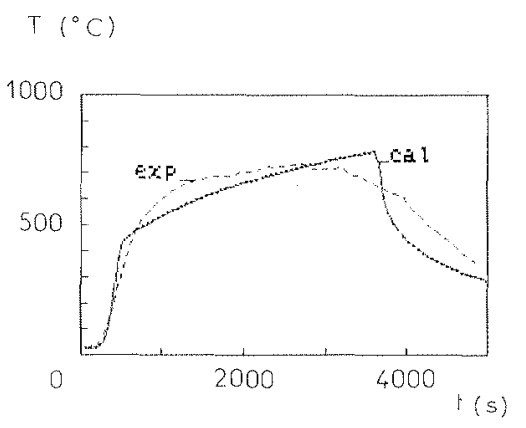

figure 5

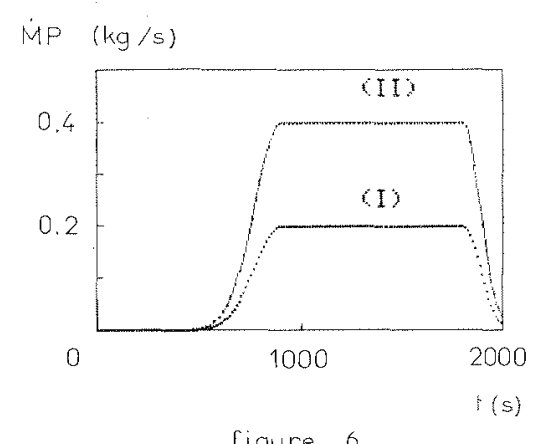

figure 6 


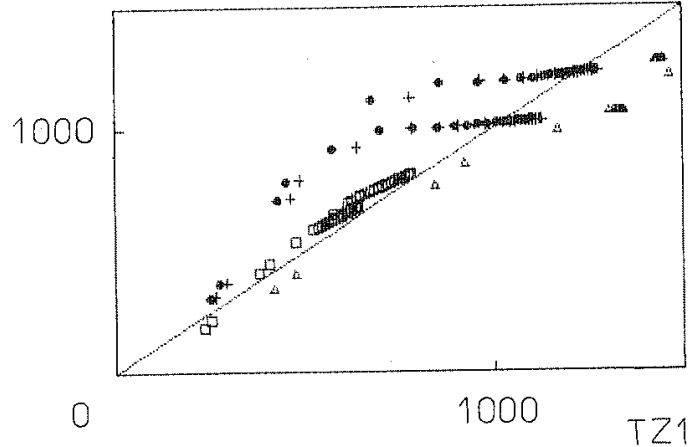

figure 7

\section{COMPARISON}

Between TCF and TZ1 :

- mass loss rate is given at figure 6

- Room :

$4.5 \mathrm{~m} \mathrm{x} 4.5 \mathrm{~m} \mathrm{x} 2.5 \mathrm{~m}$

- Opening :

$2.2 \mathrm{mx} 0.95 \mathrm{~m}$

- Thermal properties of walls (see table 3)

\section{TABLE 4}

\section{CONCLUSIONS and REMARKS}

- Fire models for short term engineering applications should be simple to use and demanding short computer times.

- Four fire models of this type are presented here aiming at the prediction of temperature evolution in a compartment fire.

- The models should not consume computer time for the calculation of variables that are not necessary to answer a given question. In the design of such models one has then to choose which variables are to be calculated (Wall temperatures for Fire Resistance, Critical delay for flashover prediction, egress time for people evacuation,...

- The physical description of fire phenomena is more or less approximate. To represent the influence of both the unknown data and the poorly described phenomena, stochastic approaches are useful in association with deterministic models.

- The capabilities of fire models for Fire Engineering applications should be evaluated through the quality of the predictions from general Fire Safety models in which they would be included.

\section{NOMENCLATURE}

A

A op

C

$\mathrm{C}_{\mathrm{p}}$ surface area of enclosure

area of opening

specific heat of solid

specific heat at constant pressure 
e

$\varepsilon$

g.

$\mathrm{H}_{\mathrm{C}}$

H

k

$\dot{\mathrm{m}}_{\mathrm{p}}$

$\dot{Q}$

$\rho$

$\rho_{0}$

$\mathrm{T}_{0}$

$\mathrm{T}_{\mathrm{u}}$

${ }^{\mathrm{r}} \mathrm{g}$

$\Delta \mathrm{T}$

$t$

$\mathrm{t}_{\mathrm{p}}$ thickness (walls)

surface emissivity

gravitationnal acceleration

heat of combustion of fuel

vertical opening dimension

thermal conductivity

mass rate of fuel supply

rate of heat release

density of gas

density of ambient air

initial or ambient air temperature

temperature of upper gas layer

post-flashover gas temperature

temperature rise of hot gas

time

thermal penetration time 


\section{REFERENCES}

1. B.H. McCAFFREY, J.G. QUINTIERE and M.F. HARKLEROAD, "Estimating Room Temperatures and the Likelihood of Flashover using Fire Test Data Correlations", Fire Techno1., 17, 2, May 1981.

2. J.G. QUINTIERE, "A Simple Correlation for Predicting Temperature in a Room Fire", Nat. Bur. Stand., NBSIR 83-2712.

3. J. BLOQWVIST and B. ANDERSSON, "Modelling of Furniture Experiments with Zone Models", Res. Report from Division of Building Fire Safety and Technology - LUND Institue of Technology, presented at the 16 th meeting of CTB Commission W14, Borehamwood, UK, May 14-18 1984.

4. M. CURTAT and X. BODART, "Point sur le modèle CSTB de développement du feu dans une pièce unique", rapport CSTB Octobre 1983.

5. H.W.: EMMONS, H.E. MITLER and L.N. TREFHETEN, "Computer Fire Code III", Harvard University, Division of Applied Sciences, Home Fire Project Technical Report no 25, Jan. 1978.

6. P.A. CROCE (ed.), "A Study of Room Fire Development : the 2nd Fire Test July $1973^{\prime \prime}$, Factory Mutual Research, FMRC Sec. no 21011.4, June 1975.

7. R.L. ALPERT et a1., "Influence of Enclosure on Fire Growth, Vol.1, Test 4: Open Door and Window", Factory Mutual Research, FMRC Job I.D. no 01052.BU-4, July 1977.

8. M. CURTAT, "Modélisation du Feu à 1'Intérieur d'Un Local : Participation du Combustible en Paroi Verticale", Rapport CSTB Déc 1984, Marché numéro 82.21.286 du Ministère de 1'Intêrieur et de la Décentralisation, Direction de la Sécurité Civile.

9. P.H. THOMAS, "Testing Products and Materials for their Contribution to Flashover in Rooms", Fire and Materials, vol. 5 no 3, Sept. 1981.

10. R.B. WILLIAMSON, "Coupling Deterministic and Stochastic Modeling to Unwanted Fires", Fire Safety Journal, 3 (1980-81), 243-259.

11. K. KAWAGOE and T. SEKINE, "Estimation of Fire Temperature-Time Curve in Rooms", BRI. Occasionnal Report no 11, Building Research Institute, Tokyo, 1963 . 
12. S.E. MAGNUSSON and THEIE ANDERSSON, "Temperature-Time Curve of Complete Precess of Fire Development", LUND Institute of Technology, SWEDEN, Bu11. no 16,1970 .

13. V. BABRAUSKAS, "COMPF2, A Program for Calculating Post-Flashover Fire Temperatures", Nat. Bur. Stand., Tech. Note 991,1979 UCB-FRG $716-16$, Nov. 1976 .

14. V. BABRAUSKAS, "A Closed Form Approximation for Post-Flashover Compartment Fire Temperatures", Fir! Safety Journal, no 4, 1981.

15. V. BABRAUSKAS and R.B. WILLIAMSON, "Post-Flashover Compartment Fires : Basis of a Theoretical Model", Fire Mater., 2, p. 39, 1978.

16. P. FROMY, Thesis report under preparation, CSTB, 1985.

17. M. CURTAT and P. FROMY, "Modèle Z1 de feu développé dans une pièce", Rapport CSTB, Mai 1985.

18. J.G. TOURRETHE, "Compte-Rendu sur la deuxième et la troisième série d'essais CSTB", Convention no 77.61.154 avec le Ministère de 1'Urbanisme et du Logement, Rapport CSTB, 1980. 